\title{
Comparison of Monitoring Techniques for Intraoperative Cerebral Ischemia
}

\author{
David W. Rowed, David A. Houlden, Lee M. Burkholder, Amanda B. Taylor
}

\begin{abstract}
Objective: To prospectively compare somatosensory evoked potentials, electroencephalography (EEG) and transcranial Doppler ultrasound (TCD) for detection of cerebral ischemia during carotid endarterectomy (CEA). Methods: Somatosensory evoked potentials and EEG recordings were attempted in 156 consecutive CEAs and TCD was also attempted in 91 of them. Recordings from all three modalities were obtained for at least 10 minutes before CEA, during CEAand for at least 15 minutes after CEA. Somatosensory evoked potentials peak-to-peak amplitude decrease of $>50 \%$, EEG amplitude decrease of $>75 \%$, and ipsilateral middle cerebral artery mean blood flow velocity (mean $\mathrm{V}_{\mathrm{MCAi}}$ ) decrease $>75 \%$ persisting for the entire period of internal carotid artery occlusion were individually considered to be diagnostic of cerebral ischemia. Clinical neurological examination was performed immediately prior to surgery and following recovery from general anaesthesia. Results: Somatosensory evoked potentials, EEG, and TCD were successfully obtained throughout the entire period of internal carotid artery occlusion in $99 \%, 95 \%$, and $63 \%$ of patients respectively. Two patients (1.3\%) suffered intraoperative cerebral infarction detected by clinical neurological examination and subsequent magnetic resonance imaging. Somatosensory evoked potentials accurately predicted intraoperative cerebral infarction in both instances without false negatives or false positives, EEG yielded one false negative result and no false positive results and $\mathrm{V}_{\text {MCAi }}$ one true positive, four false positive and no false negative results. Transcranial Doppler ultrasound detection of emboli did not correlate with postoperative neurological deficits. Nevertheless the sensitivity and specificity of each test was not significantly different than the others because of the small number of disagreements between tests. Conclusion: A > 50\% decrease in the cortically generated P25 amplitude of the median somatosensory evoked potentials, which persisted during the entire period of internal carotid artery occlusion, appears to be the most reliable method of monitoring for intraoperative ischemia in our hands because it accurately detected both intraoperative strokes with no false positive or false negative results.
\end{abstract}

RÉSUMÉ: Comparaison de techniques de surveillance de l'ischémie cérébrale peropératoire. Objectif: Comparer de façon prospective les potentiels évoqués somesthésiques, l'électroencéphalographie (ÉEG) et l'ultrasonographie Doppler transcranienne (DTC) pour détecter l'ischémie cérébrale pendant l'endartérectomie carotidienne (EAC). Méthodes: On a tenté d'enregistrer les potentiels évoqués somesthésiques et l'ÉEG chez 156 cas d'EAC consécutifs et le DTC chez 91 d'entre eux. Les trois types d'enregistrements ont été effectués pendant au moins 10 minutes avant l'EAC, pendant l'EAC et pendant au moins 15 minutes après l'EAC. On a considéré qu'il existait de l'ischémie cérébrale si l'amplitude de pic à pic des potentiels évoqués somesthésiques était diminuée de plus de 50\%, l'amplitude ÉEG était diminuée de plus de $75 \%$ ou la vélocité moyenne du flot sanguin de l'artère cérébrale moyenne ipsilatérale (VACMi) était diminuée de plus de 75\% pendant toute la durée de l'occlusion de la carotide interne. Un examen neurologique a été fait immédiatement avant la chirurgie et au réveil, après l'anesthésie générale. Résultats: Les potentiels évoqués somesthésiques, l'ÉEG et le DTC ont été enregistrés avec succès pendant toute la durée de l'occlusion de la carotide interne chez 99\%, 95\% et 63\% des patients respectivement. Pendant la chirurgie, deux patients $(1,3 \%)$ ont subi un infarctus cérébral qui a été détecté par l'examen neurologique et subséquemment par l'imagerie par résonance magnétique. Les potentiels évoqués somesthésiques ont prédit avec exactitude l'infarctus cérébral peropératoire dans les deux cas, sans qu'il y ait de faux négatif ou de faux positif. L'ÉEG a donné lieu à un faux négatif et aucun faux positif; la VACMi un positif confirmé, quatre faux positifs et aucun faux négatif. La détection de l'embolie par DCTn'avait pas de corrélation avec un déficit neurologique postopératoire. La sensibilité et la spécificité de chaque test n'étaient pas significativement différentes entre les tests à cause du peu de discordances observées. Conclusion: Selon notre expérience, une baisse de plus de 50\% de l'amplitude des composantes à courte latence P25 des potentiels évoqués somesthésiques médians, qui persistait pendant toute la durée de l'occlusion de la carotide interne, semble être la méthode la plus fiable de surveillance de l'ischémie pendant la chirurgie. Cette méthode a permis de détecter avec exactitude les deux accidents vasculaires cérébraux survenus pendant la chirurgie, sans qu'il y ait de faux positifs ou de faux négatifs.

Can. J. Neurol. Sci. 2004; 31: 347-356

Carotid endarterectomy (CEA) is an excellent model for studying potential intraoperative cerebral ischemia under controlled physiological conditions and, accordingly, many different monitoring techniques have been employed over many years, giving rise to an extensive literature on the subject. Techniques for monitoring include local anaesthesia with the
From the Department of Surgery, Division of Neurosurgery (DWR); Department of Surgical Monitoring (DAH, LMB, ABT); Sunnybrook and Women's College Health Sciences Centre, University of Toronto, Toronto, ON, Canada. ReCeived MAy 2, 2003. ACCEPTED INFINALForm DeCEMBER 16, 2003. Reprint requests to: David W. Rowed, Division of Neurosurgery, Sunnybrook and Women's College Health Sciences Centre, Suite A 134, 2075 Bayview Ave., Toronto, ON, Canada M4N 3M5. 
patient squeezing a noise making device, ${ }^{1}$ internal carotid artery (ICA) stump pressure, ${ }^{2,3}$ electroencephalography (EEG), ${ }^{4-9}$ regional cerebral blood flow (rCBF), ${ }^{10,11}$ somatosensory evoked potentials (SSEP), ${ }^{12-16}$ transcranial Doppler ultrasound (TCD) ${ }_{17-23}$ near-infrared cerebral oximetry, ${ }^{24,25}$ and jugular bulb venous oxygen saturation. ${ }^{26}$

Carotid endarterectomy is widely practiced in a variety of hospitals and under variable circumstances but guidelines and standards for intraoperative monitoring are lacking. A recent German survey, for example, found that $43 \%$ of hospitals did not perform any type of cerebral monitoring during carotid surgery. ${ }^{27}$ This sample is likely to be representative of practice in most technologically sophisticated countries and suggests that adoption of a single monitoring method which is easily performed and known to be reliable would lead to more widespread application of monitoring. There is much experience and opinion regarding various monitoring techniques and the criteria for indicating cerebral ischemia. Consequently, surgeons looking for guidance regarding the simplest and most effective method of routine monitoring are likely to experience some confusion. Direct measurement of rCBF is appealing, but logistically difficult and unlikely to be practiced widely as a routine method of CEA monitoring. Other methodologies e.g. EEG, SSEP, and TCD are more easily applied in a clinical setting, ${ }^{28}$ but there is limited guidance in the literature regarding the relative reliability and value of each method. Comparative studies are few and are limited to comparison of only two techniques in almost all instances., ${ }^{2,15,29}$ Uncertainty and confusion about methodology is probably an important reason why routine intraoperative cerebral ischemia monitoring is not more widely practiced. Consequently it is necessary to compare concurrent SSEP, EEG and TCD monitoring to determine the most reliable and valid method of preventing intraoperative cerebral infarction during CEA.

\section{METHODS}

\section{Patient population}

Carotid endarterectomy with physiological monitoring was performed on 156 patients over a four year period at Sunnybrook and Women's College Health Sciences Centre. Eighty-seven percent were symptomatic $(n=134)$. The mean percent stenosis was $85 \%$ on angiography by NASCET (North American Symptomatic Carotid Endarterectomy Trial $)^{30}$ criteria. Sixtyseven percent were males and the mean age was 70 (range $=48$ 88). All patients were anaesthetized with a combination of isoflurane, nitrous oxide, oxygen and fentanyl or remifentanil. Vecuronium/pancuronium was used during induction of anaesthesia, and subsequently allowed to wear off.

\section{SSEP}

After the patient was anaesthetized, left then right median nerves were stimulated at the wrist in an interleaving pattern. The stimulus intensity was twice that necessary to evoke a visible thenar muscle twitch before the administration of muscle relaxants. The stimulus duration was $0.2 \mathrm{~ms}$ and the stimulus rate was $3.1 \mathrm{~Hz}$. Recordings were obtained from Grass needle electrode pairs (G1-G2; Grass Instrument Co., Quincy Massachusetts) placed over the $\mathrm{C} 2$ spinous process (Cv2) - frontal scalp (Fpz), and the scalp overlying the contralateral somatosensory cortex (C3' or C4') - Fpz (International 10-20 system). ${ }^{31}$ Each two-channel average contained between 100 and 200 responses. The amplifier bandpass was $30-500 \mathrm{~Hz}$, and the time base was $70 \mathrm{~ms}$. Left and right median SSEPs were updated once every 35-70 seconds to look for SSEP changes. A $>50 \%$ decrease in the cortically generated P25 amplitude (measured from the N20 peak to P25 trough; recorded from C3' or C4' Fpz) that persisted for the entire ICA occlusion period was considered to be a significant SSEP change, provided the subcortical SSEPs did not change. ${ }^{15}$ Baseline P25 amplitude was the average of the last three measurements prior to CEA. Somatosensory evoked potentials recordings continued from at least 10 minutes before CEAto at least 15 minutes after CEAso that late changes could be detected.

\section{EEG}

Four channels of raw EEG were continuously recorded using Grass needle electrodes placed on the scalp over temporoparietal and fronto-parietal regions (T3-C3', T4-C4', F3-C3' and F4-C4') to detect EEG change during CEA. The recording bandpass was $1-70 \mathrm{~Hz}$. The EEG amplitude and frequency were measured from two seconds of raw EEG obtained immediately after each SSEP from at least 10 minutes before CEA to 15 minutes after CEA. In addition, we continuously monitored EEG to allow for quick detection and documentation of sudden EEG change, whenever it occurred. Baseline EEG amplitude and frequency was the average of the last three measurements prior to CEA. A $>75 \%$ decrease in the amplitude of all activity that persisted for the entire ICA occlusion period was considered a significant EEG change. ${ }^{5}$

\section{TCD}

The mean blood flow velocity in the middle cerebral artery (MCA) ispsilateral to surgery $\left(\mathrm{V}_{\mathrm{MCAi}}\right)$ was continuously measured using TCD ultrasonography (Neuroguard Plus, Nicolet Biomedical Inc., Golden, $\mathrm{CO}$ ) and continuously recorded on digital audio tape. Typically, the MCA was insonated at a depth of $45-55 \mathrm{~mm}$ using a TCD signal with a frequency of $2 \mathrm{MHz}$. The mean $\mathrm{V}_{\mathrm{MCAi}}$ was documented after each SSEP (35-70 seconds) from at least 10 minutes before CEA to 10-15 minutes after CEA. Continuous TCD monitoring allowed for detection of sudden change in $\mathrm{V}_{\mathrm{MCAi}}$ or detection of emboli in the MCA. Special attention was given to the TCD audio for the presence of emboli characterized by short duration $(<0.1$ second), high intensity, unidirectional signal (3-60dB above background MCA blood flow). ${ }^{32}$ The number of emboli was counted, but this was sometimes difficult due to superimposition of one embolus over another. Baseline mean $\mathrm{V}_{\mathrm{MCAi}}$ was the average of the last three measurements prior to CEA. More than $75 \%$ decrease in mean $\mathrm{V}_{\text {MCAi }}$ that persisted for the entire period of ICA occlusion was considered significant. ${ }^{7}$

\section{Operative procedure}

Neurosurgeons and vascular surgeons at our institution performed the operative procedures. Physiological monitoring feedback was given to the surgeon by the monitoring team according to the above criteria. Shunts were used at the surgeon's discretion, since there was no intent to influence treatment during the study. 


\section{Outcome measures}

A full clinical neurological examination was performed by the neurosurgical service in the recovery room after the patient emerged from anaesthetic and compared to the preoperative neurological examination. The neurological examination was repeated prior to discharge from the hospital.

\section{Statistical procedures}

Patients with persistent significant change in SSEP throughout the entire period of ICAocclusion were compared to those with no persistent change in a fourfold table of outcome (neurologically unchanged or neurologically deteriorated) versus SSEPto determine the sensitivity and specificity of SSEPchange and stable SSEP. Positive and negative predictive values were also determined. The sensitivity and specificity of persistent significant EEG change and stable EEG, persistent significant mean $\mathrm{V}_{\mathrm{MCAi}}$ change and stable mean $\mathrm{V}_{\mathrm{MCAi}}$, and the presence and absence of emboli were compared using the same statistical procedures used for SSEP data (described above). Positive and negative predictive values were also determined for EEG, mean $\mathrm{V}_{\mathrm{MCAi}}$ and emboli. The ability of each of the three monitoring techniques to correctly predict intraoperative stroke was compared by the McNemar test.

\section{RESULTS}

\section{Clinical outcomes}

In 156 patients subjected to CEA, there were two who experienced new immediate neurological deficits which persisted for more than 24 hours (immediate cerebral infarction) $(1.3 \%)$. There were two other patients who did not demonstrate any new neurological deficit in the immediate postoperative assessment, but subsequently experienced onset of a new and persisting neurological deficit (delayed cerebral infarction, presumably embolic) (1.3\%). The overall stroke rate for the series was thus $2.6 \%$, equally divided between immediate and delayed strokes. There were no perioperative deaths.

\section{Reliability of monitoring techniques}

Median SSEP responses adequate for monitoring purposes were obtained throughout the entire operative procedure in $155 / 156$ patients $(99.4 \%)$. Continuously monitorable EEG was present throughout the operation in $148 / 156$ patients $(94.9 \%)$. Transcranial Doppler ultrasound flow velocity could be measured continuously throughout the procedure in 57/91 cases $(62.6 \%)$.

\section{Predictive value of SSEP, EEG and TCD}

Somatosensory evoked potentials showed sensitivity, specificity, positive and negative predictive values of 1.000 $(\mathrm{N}=155)$. The corresponding values, respectively, for EEG were $0.500,1.000,1.000$ and $0.993(\mathrm{~N}=148)$ and for TCD mean $\mathrm{V}_{\text {MCAi }}$ were $1.000,0.929,0.200$, and $1.000(\mathrm{~N}=57)$. These values must be considered in the context of a low perioperative stroke rate. The McNemar test showed no significant difference between SSEPand EEG $(\mathrm{P} \leq 1)$, SSEP and TCD $(\mathrm{P} \leq 0.125)$, and EEG and TCD $(\mathrm{P} \leq 1)$, likely because of the small number of patients who had one test correctly predicting outcome when the other test was incorrect. From our cohort of 156 patients it is estimated that a sample size of 280 patients would be necessary to achieve $80 \%$ power to detect an odds ratio of at least 5.0 using a one-sided McNemar test with a significance level of 0.05 (PASS 2000; Power analysis and sample size for Windows, NCSS, Paysville, Utah).

\section{Median SSEP}

Of the 155 patients in whom median SSEP monitoring could be successfully obtained during the entire period of ICA occlusion, three (1.9\%) demonstrated temporary significant changes, consisting of a $>50 \%$ amplitude decrease that recovered before the end of the ICA occlusion time, and two (1.3\%) showed significant changes that persisted until the end of occlusion. Two of the three patients with temporary significant changes in SSEP(Patients 5 and 6, Table 1) were managed with intraluminal shunts, which reversed the SSEP changes. In the fourth patient (Patient 4), the SSEP changes reversed

\section{Table 1: Summary of significant SSEP, EEG or TCD changes}

\begin{tabular}{lccccccc}
\hline Patient \# & ID/age & $\begin{array}{c}\text { ICAocclusion } \\
\text { time (mins.) }\end{array}$ & Shunt & SSEP $\Delta$ & EEG $\Delta$ & $\begin{array}{c}\text { TCD } \Delta \\
\left(\mathrm{V}_{\text {MCA }}\right)\end{array}$ & $\begin{array}{c}\text { New, immediate } \\
\text { neurologic deficits* }\end{array}$ \\
1 & JA/78 & 37 & $\mathrm{y}$ & $\mathrm{P}$ & $\mathrm{P}$ & $\mathrm{ND}$ & $\mathrm{y}$ \\
2 & $\mathrm{GH} / 70$ & 16 & $\mathrm{n}$ & $\mathrm{P}$ & $\mathrm{n}$ & $\mathrm{P}$ & $\mathrm{n}$ \\
3 & $\mathrm{EA} / 73$ & 33 & $\mathrm{n}$ & $\mathrm{n}$ & $\mathrm{n}$ & $\mathrm{P}$ & $\mathrm{n}$ \\
4 & $\mathrm{DB} / 68$ & 28 & $\mathrm{n}$ & $\mathrm{T}$ & $\mathrm{n}$ & $\mathrm{n}$ & $\mathrm{n}$ \\
5 & $\mathrm{RS} / 71$ & 24 & $\mathrm{y}$ & $\mathrm{Rs}$ & $\mathrm{Rs}$ & $\mathrm{ND}$ & $\mathrm{n}$ \\
6 & $\mathrm{~GB} / 72$ & 28 & $\mathrm{y}$ & $\mathrm{Rs}$ & $\mathrm{Rs}$ & $\mathrm{ND}$ & $\mathrm{n}$ \\
7 & $\mathrm{ED} / 66$ & 37 & $\mathrm{y}$ & $\mathrm{n}$ & $\mathrm{Rs}$ & $\mathrm{n}$ & $\mathrm{n}$ \\
8 & $\mathrm{MB} / 71$ & 44 & $\mathrm{y}$ & $\mathrm{n}$ & $\mathrm{n}$ & $\mathrm{Rs}$ & $\mathrm{n}$ \\
9 & $\mathrm{HG} / 74$ & 29 & $\mathrm{n}$ & $\mathrm{n}$ & $\mathrm{n}$ & $\mathrm{P}$ & $\mathrm{n}$ \\
10 & $\mathrm{RN} / 67$ & 21 & $\mathrm{n}$ & $\mathrm{n}$ & $\mathrm{n}$ & $\mathrm{P}$ & $\mathrm{n}$ \\
11 & $\mathrm{JS} / 71$ & 43 & $\mathrm{n}$ & $\mathrm{n}$ & $\mathrm{n}$ & $\mathrm{P}$ & \\
\end{tabular}

$\mathrm{y}=$ yes; $\mathrm{n}=\mathrm{no} ; \mathrm{P}=$ persistent (significant change that persisted to the end of ICA occlusion); $\mathrm{T}=$ temporary (significant change that resolved spontaneously by 3 minutes); Rs = reversible with shunt (significant change that reversed with intraluminal shunt; change lasted 3-10 minutes); $\mathrm{ND}=$ not done: * lasting >24 hours; SSEP=somatosensory evoked potentials; $\mathrm{EEG=electroencephalogram;} \mathrm{TCD=trancranial} \mathrm{Doppler.}$ 


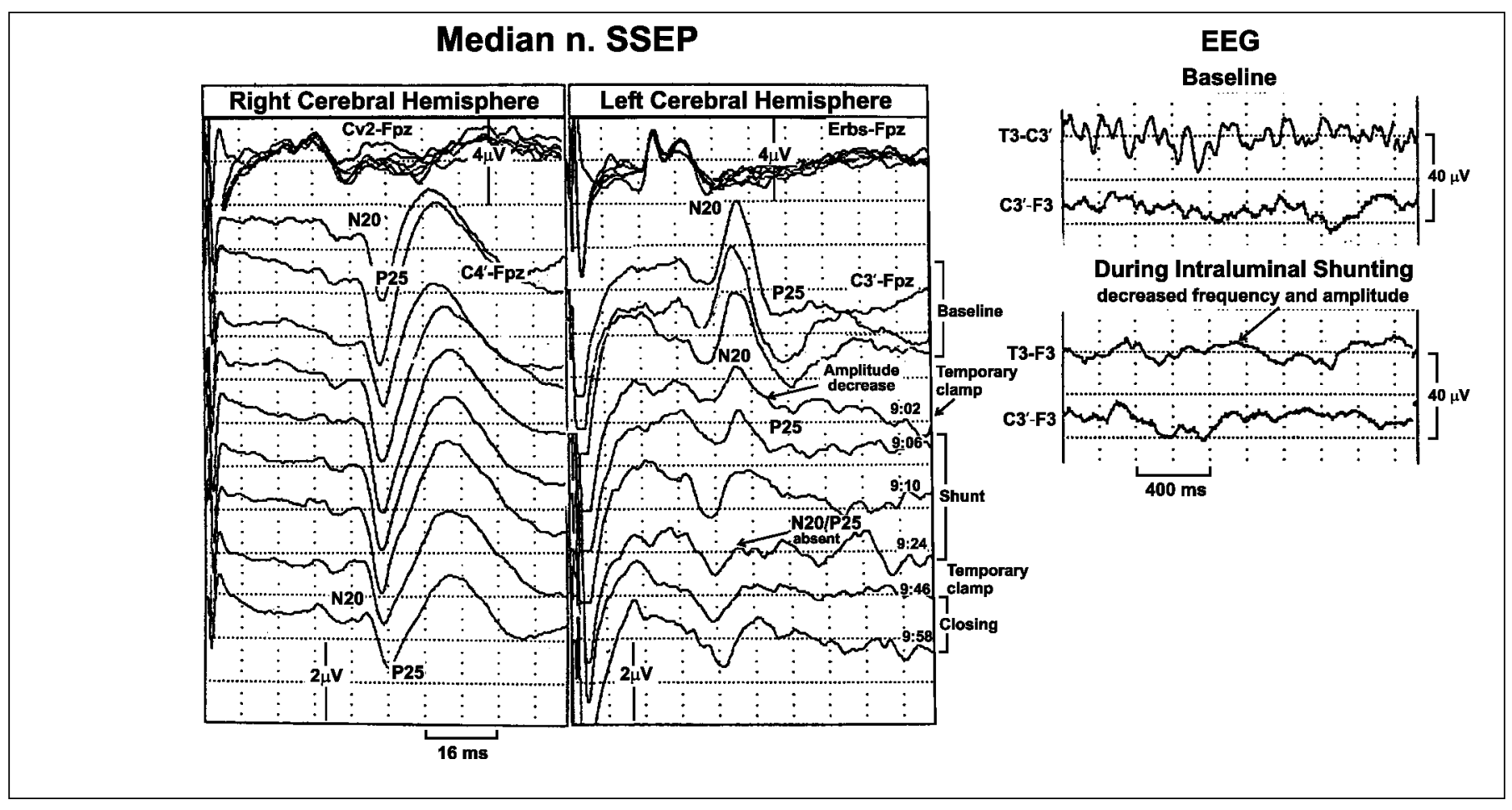

Figure 1: Following left ICAocclusion, the left cerebral hemisphere (right median) SSEP decreased during temporary clamping for shunt placement, but did not recover after the shunt was placed. Rather, the SSEPcontinued to diminish rapidly until the P25 response was absent, accompanied by EEG amplitude decrease and slowing. Intraluminal shunt placement therefore did not reverse the electrophysiological changes and the patient experienced a new, persisting right hemiplegia, right conjugate gaze palsy and dysphasia which was evident immediately in the postanaesthetic recovery room (immediate cerebral infarction). The probable cause was shunt obstruction due to the distal end being pressed against the arterial wall. This remains unproven but the timing of SSEP decrease does not favor an embolic etiology and demonstrated patency of the shunt lumen at the conclusion of the procedure effectively eliminates thrombosis within the shunt as an explanation for its failure to reverse SSEP change.

spontaneously within three minutes of clamping without insertion of a shunt (Figure 4).

None of the three patients with temporary significant SSEP change experienced a perioperative neurological deficit. The longest period of temporary significant change was 10 minutes (Patient 5, Table 1, and Figure 2). In contrast, the two patients (Patients 1 and 2, Table 1) with significant SSEP changes that persisted until the end of ICA occlusion showed immediate and lasting deficits that correlated with postoperative CT or MR evidence of cerebral infarction. In these two patients, SSEP change persisted until the end of monitoring (at least 15 minutes after CEA), Accordingly, the positive predictive value of a persistent significant SSEP change was 1.000 and the negative predictive value was also 1.000 . One of these two patients was managed with an intraluminal shunt within two minutes after SSEP change but this did not reverse the SSEP deterioration (Figure 1). The endarterectomy took 31 minutes to perform. The second patient was not shunted, and the period of internal carotid occlusion lasted 16 minutes.

\section{Continuous EEG}

Of the 148 patients in whom EEG could be recorded continuously throughout ICA occlusion time, three $(2.0 \%)$ showed temporary significant changes consisting of amplitude decreases of $>75 \%$ with reduction or loss of fast components, returning to baseline before the end of ICA occlusion. All three of these patients were managed with intraluminal shunts and none experienced new perioperative neurological deficits (Table 1, Patients 5,6,7). One other patient (Patient 1) $(0.7 \%)$ demonstrated persisting significant EEG changes, beginning almost immediately after ICAocclusion and lasting until the end of monitoring (at least 15 minutes post CEA). This patient had a new and persisting neurological deficit, which was seen immediately in the postanaesthetic recovery room (immediate cerebral infarction). The EEG was recorded in real time while SSEP required signal averaging for up to one minute thereby minimally delaying interpretation of the SSEP (Figure 1). One further patient (Patient 2) in whom there were no significant intraoperative EEG changes experienced a new neurological deficit that was present on emergence from anaesthesia (immediate cerebral infarction). Accordingly, the positive predictive value of continuous EEG was 1.000 and the negative predictive value was 0.993 .

\section{TCD - mean $\mathrm{V}_{\text {MCAi }}$}

Of the 57 patients in whom reliable TCD data were available throughout the procedure, six $(10.5 \%)$ showed temporary significant decreases in mean $\mathrm{V}_{\mathrm{MCAi}}$. (Patients 2,3,8,9,10,11, Table 1). Only one (Patient 8) was managed with shunt insertion, which reversed the decrease in $\mathrm{V}_{\mathrm{MCAi}}$ The other five had significant decreases in $\mathrm{V}_{\text {MCAi }}$ that occurred almost immediately after ICA occlusion and remained decreased during the entire period of ICA 


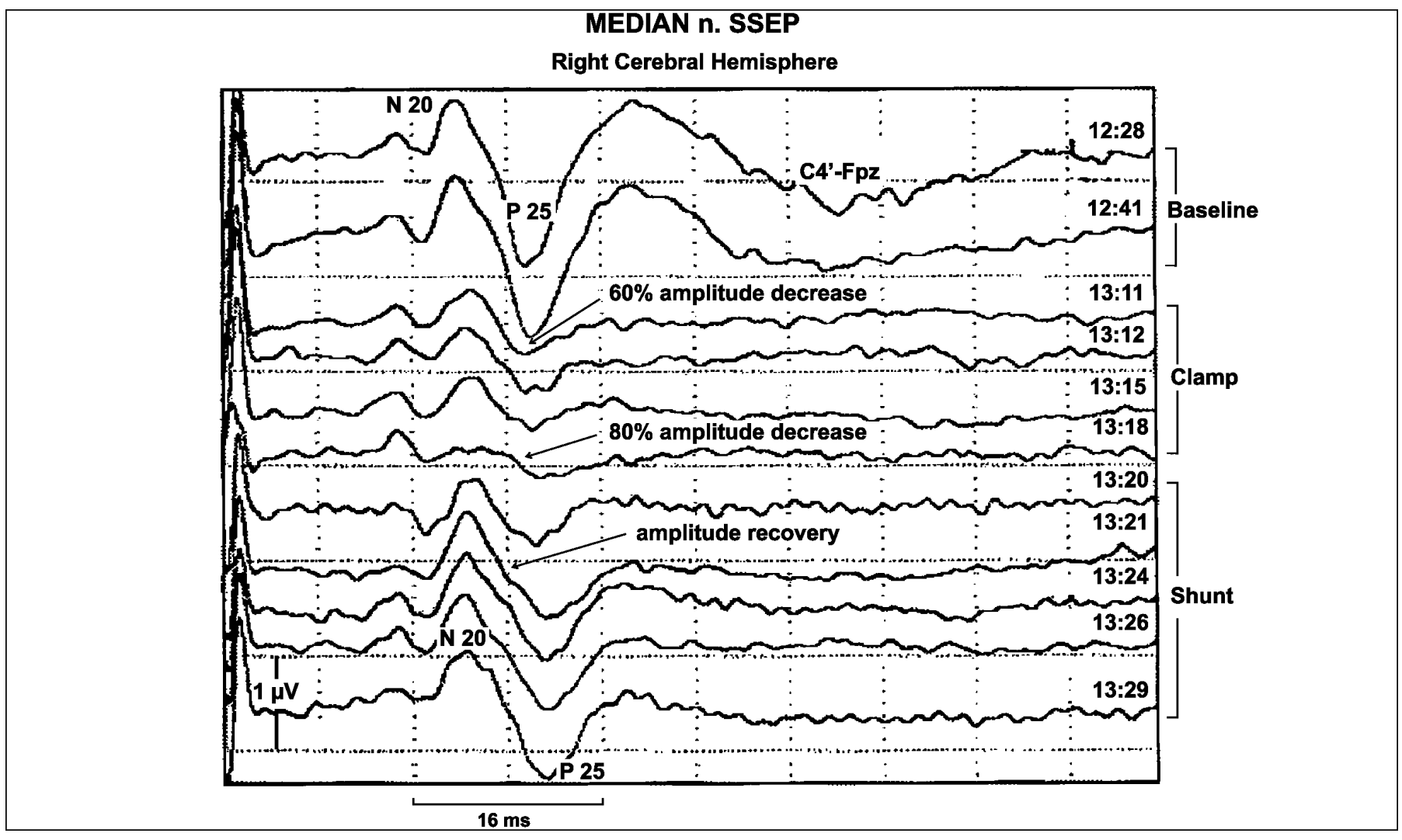

Figure2: Following right ICAocclusion, the right hemisphere (left median) SSEPamplitude decreased, within two minutes, by $60 \%$ of its preocclusion value. Over the ensuing seven minutes there was a further decrease in amplitude to only $20 \%$ of preocclusion value. An intraluminal shunt was then placed and SSEP amplitude gradually returned to baseline value. The patient did not suffer any new neurological deficit as a result of CEA, despite eight to nine minutes of significant SSEP amplitude decrease, remaining intact in the postanaesthetic recovery room.

occlusion (range $=21-43$ minutes) (Figure 3 ). One patient (Patient 2) experienced a new and persisting focal neurological deficit that was immediately evident in the postanaesthetic recovery room (immediate cerebral infarction). Importantly, this patient also had persistent SSEPchanges, but did not demonstrate any EEG change. An intraluminal shunt was not employed. A CT subsequently confirmed cerebral infarction (true positive result). The other four did not experience any new neurological deficit (false positive results). These false positive results caused the positive predictive value of mean $\mathrm{V}_{\mathrm{MCAi}}$ to fall to 0.2 .

Table 2: A comparison of sensitivity and specificity of SSEP and/or EEG and TCD ( $\left.\mathrm{V}_{\mathrm{MCA}}\right)$ to intraoperative stroke during carotid endarterectomy

\begin{tabular}{|c|c|c|c|c|c|c|c|c|c|}
\hline \multirow[t]{2}{*}{ Author } & \multirow{2}{*}{$\begin{array}{l}\text { Total } \\
\text { Cases }\end{array}$} & \multicolumn{3}{|c|}{ Sensitivity } & \multicolumn{3}{|c|}{ Specificity } & \multirow{2}{*}{\multicolumn{2}{|c|}{$\begin{array}{l}\text { Immed. Year } \\
\text { Post Op } \\
\text { Stroke Rate }(\%)\end{array}$}} \\
\hline & & $\operatorname{SSEP}(n)$ & EEG (n) & $\mathbf{V}_{\text {MCA }}(\mathbf{n})$ & $\operatorname{SSEP}(n)$ & EEG (n) & $\mathbf{V}_{\mathrm{MCA}}(\mathbf{n})$ & & \\
\hline Rowed, et al & 156 & $1(155)$ & $0.5(148)$ & $1(57)$ & $1(155)$ & $1(148)$ & $0.93(57)$ & 1.3 & 2004 \\
\hline de Boorst, et al ${ }^{33}$ & 599 & nd & no report & $0.33(598)$ & nd & no report & no report & 0.7 & 2001 \\
\hline Dunne, et $\mathrm{al}^{47}$ & 41 & nd & na & na & nd & $0.94(32)$ & $0.88(32)$ & 0 & 2001 \\
\hline Fiori, et $\mathrm{al}^{32}$ & 166 & na & na & na & $0.99(153)$ & $0.99(153)$ & 0.99 (153) & 0 & 1997 \\
\hline Arnold, et al ${ }^{48}$ & 82 & nd & $1(71)$ & $1(71)$ & nd & $0.94(71)$ & $0.96(71)$ & 4.8 & 1997 \\
\hline Jansen, et $\mathrm{al}^{7}$ & 130 & nd & $0(130)$ & $0.5(123)$ & nd & $0.93(130)$ & 0.89 (123) & 1.5 & 1993 \\
\hline Thiel, et al ${ }^{40}$ & 103 & $0.75(78)$ & nd & $0.75(78)$ & $1(78)$ & nd & $0.93(78)$ & 5.1 & 1990 \\
\hline Steiger, et al ${ }^{49}$ & 100 & nd & $0.5(94)$ & $0(94)$ & nd & $0.95(94)$ & $0.87(94)$ & 2 & 1989 \\
\hline
\end{tabular}

$\mathrm{n}=$ number of cases in which there were sufficient data for calculation of sensitivity and specificity; nd=not done; na=not applicable because no immediate postoperative stroke; no report=data not provided in that report; SSEP=somatosensory evoked potentials; EEG=electroencephalogram; $\mathrm{TCD}=$ trancranial Doppler; $\mathrm{V}_{\mathrm{MCA}}=$ middle cerebral artery mean blood flow velocity 


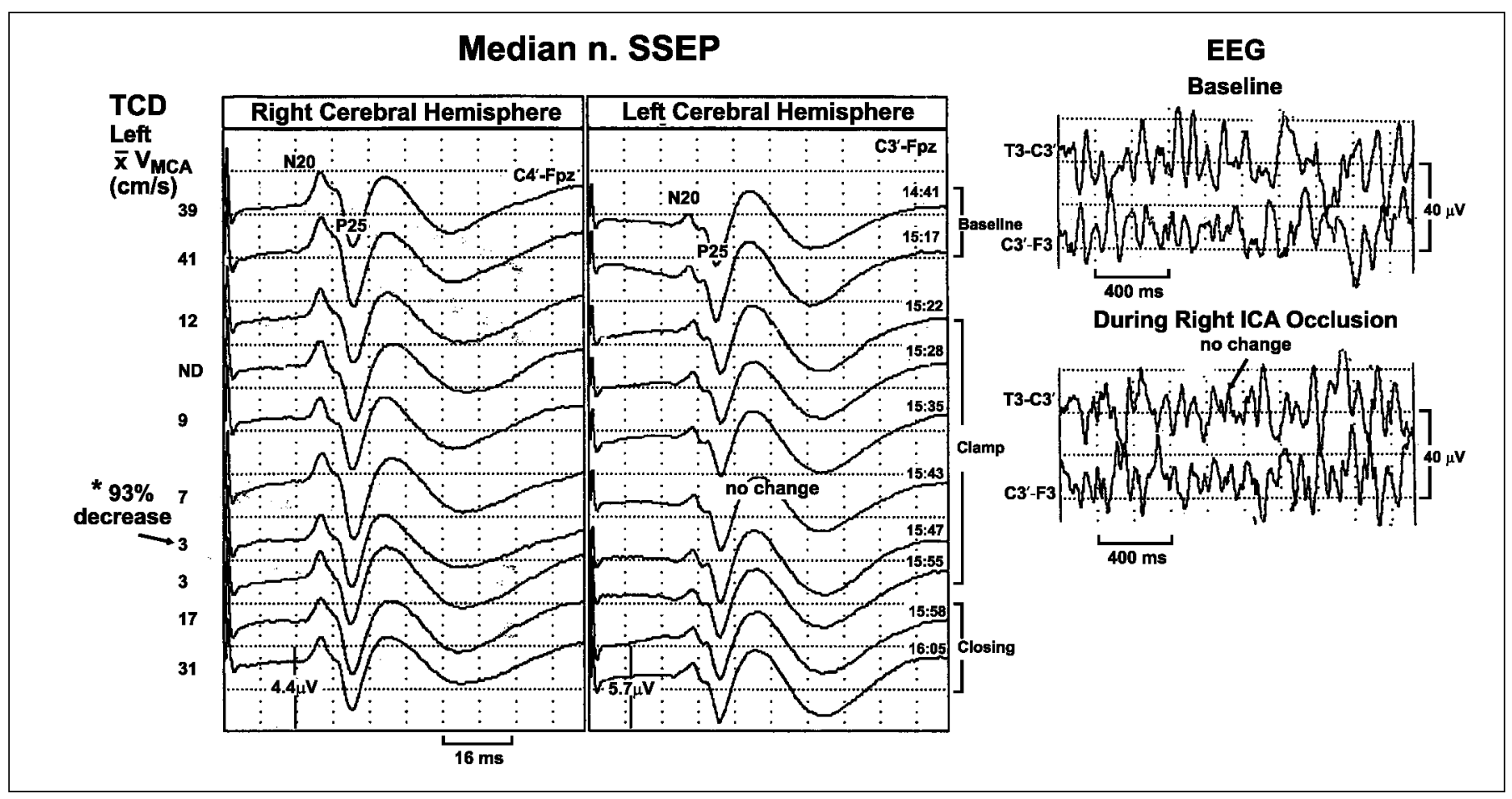

Figure 3: Immediately following right ICA occlusion, ipsilateral MCA mean TCD velocity fell by $71 \%$ of preocclusion levels but there was no change in SSEP or EEG. Flow velocity continued to decline throughout the period of right ICA occlusion, without SSEP or EEG change. The patient was neurologically intact postoperatively. Preoperative cerebral angiography showed an ipsilateral MCA, which filled only from the right ICA, without angiographically demonstrated collaterals. The probable explanation for the lack of witnessed change in the electrophysiological parameters is that collateral circulation at pial level preserved cerebral blood flow, despite a marked decrease in MCA flow.

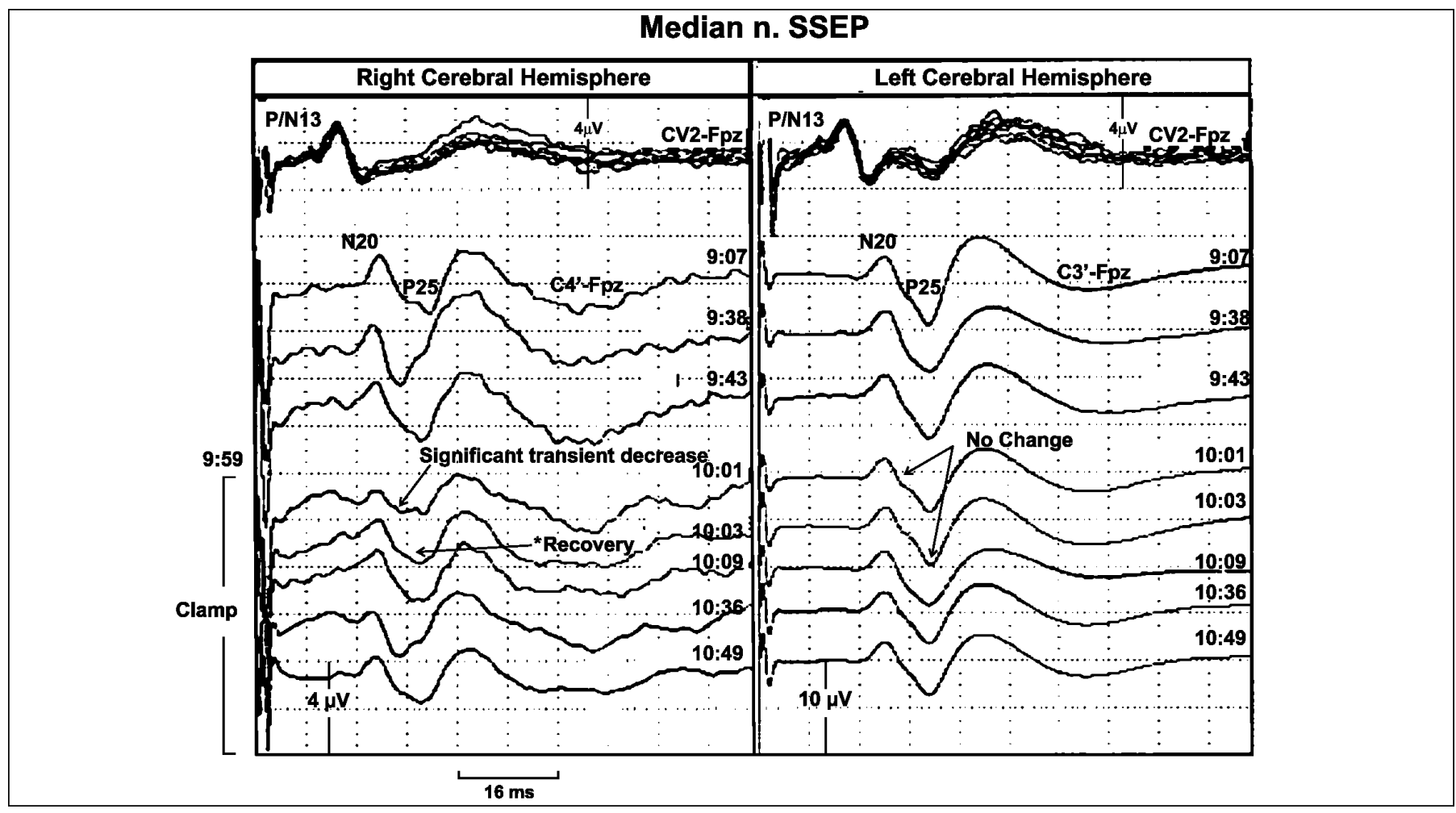

Figure 4: The SSEP recorded from the right hemisphere during right CEA showed a temporary significant change (>50\%) without a change in the subcortically generated P/N13. These changes reversed spontaneously within three minutes of clamping without insertion of a shunt. The patient remained neurologically intact in the recovery room. 


\section{TCD evidence of emboli}

Of the same 57 patients monitored throughout the procedure with TCD, 14 (24.6\%) showed signals compatible with microemboli, but none of these developed immediate or delayed neurological deficits. One patient $(1.8 \%)$ suffered a single postoperative transient cerebral ischemic attack but postoperative Doppler ultrasound did not reveal any abnormality of the operated common or internal carotid arteries and the patient has remained asymptomatic. Accordingly, the positive predictive value of microemboli for perioperative stroke was 0.000 and the negative predictive value was 1.000 .

\section{Illustrative cases}

Patient 1: Serial intraoperative median SSEP and EEG recordings from Patient 1 are shown in Figure 1. Somatosensory evoked potentials and EEG changes began almost immediately after the cross clamp and persisted until the end of monitoring. The patient suffered an immediate postoperative stroke.

Patient 5: Serial intraoperative left median SSEP recordings from Patient 5 are displayed in Figure 2. This case illustrates prolonged temporary SSEP changes corrected by shunting and not associated with new neurological deficit. Temporary EEG changes also occurred in this patient (not shown).

Patient 3: Serial intraoperative left and right median nerve SSEP recordings with corresponding TCD (mean $\mathrm{V}_{\text {MCAi }}$ ) and EEG before and during ICAocclusion are displayed in Figure 3. This case shows marked decrease in mean $V_{\text {MCAi }}$ without cortical ischemia, as reflected by lack of SSEP and EEG change.

Patient 4: Spontaneous recovery of significant SSEPchanges occurring after right ICA occlusion are illustrated in Fig 4. This patient did not suffer a neurological deficit.

\section{Discussion}

The intraoperative stroke rate was low at $2 / 156(1.3 \%)$. There were no intraoperative deaths. There were two other delayed cerebral infarctions (which could not have been prevented by intraoperative monitoring) and no postoperative deaths within 30 days. The overall stroke and death rate, therefore, was 4/156 $(2.6 \%)$. Our perioperative stroke and death rate is low compared to most published series. In NASCET, ${ }^{30}$ for example, a $5.5 \%$ overall perioperative stroke rate was observed despite use of intraluminal shunts in $40 \%$ of patients. (Routine intraoperative monitoring was not employed in NASCET). De Boorst et $\mathrm{al}^{33}$ also reported the failure of shunts to prevent intraoperative strokes in that $55 \%$ of their intraoperative strokes occurred in patients in whom shunts were used. Though the stroke rate in our series was low it might have been lower. We regard both of the strokes that occurred as potentially preventable. In the first patient the surgeon elected not to use a shunt when informed of SSEP disappearance. Since this is not a clinical outcome study, we did not insist that the surgeon respond in a standardized fashion on being informed of indications of probable cerebral ischemia. Our agreement was to inform the surgeon of significant changes. In the second case of intraoperative stroke, because of an error in communication, the surgeon was not informed of significant SSEP and EEG change, and the surgeon took no action. In that instance, the surgeon had inserted a shunt but was not made aware that SSEP and EEG changes persisted, indicating probable shunt malfunction with resulting cerebral ischemia. Though the low stroke rate increases the difficulty of correlation of clinical events with monitoring changes, the fact that such a low level of stroke morbidity was achieved suggests that routine monitoring and selective shunting may be helpful in lessening perioperative stroke risk and constitutes a strong argument for routine monitoring.

Median nerve SSEP monitoring accurately predicted intraoperative stroke in our study; a unilateral $>50 \%$ decrease inP25 amplitude that persisted to the end of ICA occlusion occurred in two patients, and both suffered new and immediate postoperative neurological deficits. Further analysis of the SSEP and neurological outcome data showed there were no false positive or false negatives. This, combined with the high success rate for obtaining intraoperative SSEP waveforms, makes median nerve SSEP testing a reliable and useful technique for monitoring brain function during CEA. The advent of new technology (i.e., digital smoothing, flexible data acquisition modes like interleaving of left and right SSEPs and especially restrictive filtering) increases stability of SSEP waveforms and facilitates faster update.

We chose a greater than $50 \%$ decrease of P25 amplitude as our criterion for significant SSEP change because others have shown that this correlates well with neurological outcome after CEA. ${ }^{13,15}$ Haupt et al ${ }^{13}$ found that this SSEP criterion accurately predicted outcome in all patients without new deficits (986 patients), and in seven of eight patients with new postoperative neurological deficits. Their one false negative appeared to have occurred near the end of the procedure after cessation of SSEP monitoring. Lam et $\mathrm{al}^{15}$ showed that this SSEP criterion resulted in no false negatives and one false positive.

Median nerve SSEP monitoring may miss intraoperative stroke that occurs outside the MCA territory ${ }^{34}$ and may be less reliable in patients with preoperative neurologic deficits ${ }^{35}$ but these limitations were not evident in our study. Perhaps our use of restrictive filtering $(30-500 \mathrm{~Hz})$, which increases the reproducibility of the SSEP waveforms from trial to trial, is important for reducing false positives and negatives.

The EEG monitoring was less reliable than SSEP monitoring in predicting intraoperative stroke. One of the two patients who sustained immediate postoperative neurological deficits did not have a significant EEG change (false negative). The four-channel EEG might not have been comprehensive enough to detect focal EEG change in a specific brain location. Eight to 16 channels have frequently been employed previously for detection of intraoperative ischemia., ${ }^{4,36}$ During the early part of the present series we lacked sufficient channels to provide more comprehensive scalp coverage. Because the electrode coverage of the head is not complete, EEG may not demonstrate changes resulting from an embolic arterial branch occlusion at cortical level. It is possible that 16 channels would provide greater sensitivity to emboli. On the other hand, both patients who suffered intraoperative hemispheric strokes had significant changes in the intraoperative SSEP, so it is surprising that the concomitant EEG monitoring failed to detect change in one of them. It is certainly possible that a subcortical stroke might be missed by EEG while affecting ascending cortical pathways and thus producing SSEP changes. Chiappa et $\mathrm{al}^{6}$ reported false negatives when analyzing EEG and neurological outcome but 
most were related to cessation of EEG monitoring before the ischemic event occurred.

Disagreement between 16 channel EEG and SSEP has been reported previously. ${ }^{15,36}$ In one study, SSEP P25 amplitude decreased $>50 \%$ during the entire period of carotid occlusion but the 16 channel EEG did not and this patient woke with new neurological deficits. ${ }^{15}$ This study was valuable because none of the patients were shunted, and the analysis of SSEP, EEG and postoperative neurological function was performed in a blinded fashion. In another study, the SSEPwas suddenly lost 24 minutes after carotid occlusion yet the eight-channel EEG remained almost unchanged, and this patient sustained a new hemiplegia. ${ }^{37}$

Although there was one false negative EEG in our study, there were no false positives. The low false positive rate may be due to the fact that only severe changes in EEG amplitude $(>75 \%$ decrease in the anaesthetic induced fast activity for the entire period of endarterectomy) were considered significant. ${ }^{5}$ Some (nonshunted) patients had significant EEG changes during carotid occlusion that spontaneously recovered before the end of the endarterectomy, and none of these had new postoperative neurological sequelae. Recovery of EEG amplitude in these patients was likely due to collateral flow. ${ }^{38}$ None of these patients had concomitant SSEP change.

Previous studies have shown that a significant change in both SSEP and EEG should be the criterion for shunting, while a change in EEG alone should not. ${ }^{36}$ We agree that reliance on EEG change alone as the sole indicator of ischemia may be unwise.

The success rate for obtaining intraoperative EEG monitoring was only slightly less than that of SSEP. Since EEG monitoring has more false negatives than SSEP, we believe it is less reliable for detection of significant intraoperative ischemia. Because it is simple and reliable it is a useful backup for SSEP.

Since we could record TCD continuously for the entire period of ICA occlusion in only $62.6 \%$ of our patients, it was less reliable for intraoperative monitoring in our hands than SSEP or EEG. There was a slight improvement in our success rate in the later part of the series, but we still failed to obtain useful recordings throughout the period of occlusion in a significant proportion of attempts. Failures were mostly attributable to a poor temporal window in this elderly population, though some were also related to inability to maintain an adequate signal throughout CEA, despite the use of a probe holding helmet and a protective shield. Some investigators have reported higher success rates. For example, Fiori et al, ${ }^{32}$ Lennard et $\mathrm{al}^{39}$ and Jansen et $\mathrm{al}^{7}$ all reported TCD success rates exceeding $85 \%$. Thiel et $\mathrm{al}^{40}$ reported an $80 \%$ success rate. Dinkel et $\mathrm{al}^{41}$ on the other hand, had a slightly lower success rate than the present study. It is unclear in many reports whether or not TCD was present throughout the entire period of ischemic risk.

Our neurophysiologists and surgeons are all experienced, committed to intraoperative monitoring, and accustomed to protecting electrodes and transducers in the surgical field. We therefore believe that, even if some experienced groups achieve a higher success rate, many will encounter a TCD failure rate comparable to ours. The greater reliability and simplicity of SSEP and EEG suggests easier applicability in CEA. This is important, given that CEA is practiced in a wide variety of hospital settings.
An amplitude decrease of $>75 \%$ in the mean velocity of flow in the ipsilateral MCA $\left(\mathrm{V}_{\mathrm{MCAi}}\right)$ was considered a significant decrease in the present study. Ackerstaff et al, ${ }^{42}$ in an analysis of 1058 patients monitored intraoperatively during CEA, found that a decrease $\geq 90 \%$ of MCA peak systolic velocity was independently associated with intraoperative cerebral infarction. Since only one of five patients in the present series who demonstrated a persisting $\mathrm{V}_{\text {MCAi }}$ decrease of $>75 \%$ suffered an immediate cerebral infarction, the level chosen for significance may be less predictive than the more stringent criterion of Aackerstaff et al. ${ }^{17}$ There were four false positive results with this criterion, which decreased the positive predictive value of TCD for intraoperative stroke. A patient (Patient 3) representative of this false positive prediction (Figure 3) deserves comment. Since there was no change in SSEP or EEG for the entire period of carotid occlusion (33 minutes) and the patient did not experience a new neurological deficit, clearly the cortical territory of the MCA was adequately perfused. The likely explanation of the observed facts is that collateral circulation was sufficient to maintain cerebral perfusion even when $\mathrm{V}_{\mathrm{MCAi}}$ was decreased. Heyer et $\mathrm{al}^{43}$ also reported conflicting indications of cerebral ischemia as detected by simultaneous EEG and TCD during CEA and Halsey et $\mathrm{al}^{44}$ showed that $\mathrm{rCBF}$ correlated with mean $\mathrm{V}_{\mathrm{MCAi}}$ only if $\mathrm{rCBF}$ was $<20 \mathrm{ml} / 100 \mathrm{gm} / \mathrm{min}$. In some patients a low $\mathrm{V}_{\text {MCAi }}$ of $15 \mathrm{~cm} / \mathrm{sec}$ could occur when $\mathrm{CBF}$, measured from the cerebral convexity, was between 25 and $30 \mathrm{ml} / 100 \mathrm{gm} / \mathrm{min}^{44}$ Accordingly, the value of TCD flow velocity as an independent monitoring technique for cerebral perfusion appears to be limited.

Emboli were detected in only about one quarter of our patients. This is a lower incidence of emboli than that reported by some other authors, ${ }^{7,32,45,46}$ but observed incidence of emboli on TCD during CEA has varied greatly in previous reports. ${ }^{46}$

Emboli were more common at the time of ICAclamp release than during dissection or endarterectomy, probably due to presence of residual air within the lumen. A higher incidence of emboli at the time of clamp release is common to most reported series. ${ }^{32,42}$ The sequence and timing of clamp removal in our procedures was intended to ensure that emboli, if present, entered the external carotid artery rather than the ICA and this may have been at least partly responsible for the lower incidence of emboli observed.

We observed no correlation between intraoperative emboli and perioperative cerebral infarction. Since none of our patients with intraoperative emboli had postoperative deficits, no conclusion can be drawn regarding the relative significance of numbers of emboli and timing of occurrence. Fiori et $\mathrm{al}^{32}$ recorded embolic signals in $68 \%$ of CEA patients intraoperatively but only one $(0.9 \%)$ suffered a new neurological deficit and therefore they were unable to ascribe any predictive value to intraoperative emboli detected by TCD. Jansen et $\mathrm{al}^{7}$ detected emboli intraoperatively in $45 \%$ of their 123 patients with only one $(1.9 \%)$ experiencing a new neurological deficit. Dunne et $\mathrm{al}^{47}$ detected postoperative emboli in $88 \%$ of cases, but with only 30 patients no clinical correlation is possible. It seems safe to conclude, however, that perioperative emboli occur very much more frequently than does perioperative infarction and, therefore, that their predictive value is probably limited. Aackerstaff et al, ${ }^{42}$ in a large series of 1058 CEA patients from 
two centers, reported statistically significant correlations between embolic signals observed during dissection (30.6\%) and during wound closure (26.6\%) with outcome. Emboli were seen during shunting, but did not correlate with outcome, and emboli seen at clamp release did not correlate with outcome, supporting the belief that these are mainly gaseous. Though this study addresses the possibility that emboli detected during different parts of the operative procedure may have differing predictive values, the overall correlation of emboli with new neurological deficits discovered on retrospective chart review was poor. Emboli occurred in up to $2 / 3$ of their patients, depending on which center and which part of the procedure is considered, but only 39 patients $(3.7 \%)$ suffered strokes.

In summary, it would appear that embolic signals following clamp release are of no value in predicting outcome. Emboli seen at other stages of the procedure may be particulate and their significance as a predictor of new neurological deficits is uncertain. By making the surgeon aware of embolic signals, operative technique may be modified. Since most surgeons are aware of the importance of gentle, careful handling of the carotid arteries in order to prevent intraoperative embolic stroke, the importance of this is uncertain. Because emboli appear to be an important cause of perioperative strokes, and TCD is the only technique, of those evaluated, that detect emboli as such, it is disappointing that its predictive value for embolic stroke is not greater.

Despite an extensive literature on cerebral monitoring in CEA, direct comparison of all three of the currently most widely used techniques is lacking. This is the first report in which all three monitoring modalities were measured simultaneously and in which intraoperative cerebral infarctions occurred. Fiori et al ${ }^{32}$ compared simultaneous monitoring of EEG, SSEP and TCD in 166 CEAs performed under general anaesthesia (Table 2). Clinical correlation was impossible in their series because, though two of their patients developed new neurological deficits $(1.2 \%)$, both were delayed in onset, i.e. no intraoperative strokes occurred. In their series, $\mathrm{V}_{\mathrm{MCAi}}$ decreases of up to $60 \%$ showed significant electrophysiological changes in only two of 20 patients $(10 \%)$. In the present series, only five of 156 patients had significant decreases in $\mathrm{V}_{\mathrm{MCAi}}$ as a result of arterial crossclamping, perhaps because a more stringent criterion of $>75 \%$ decrease in $\mathrm{V}_{\mathrm{MCAi}}$ was used and only one of our five patients (20\%) showed a concomitant significant electrophysiological change (SSEP).

Somatosensory evoked potentials, in our hands, is the most reliable indicator of ischemia in CEA. An EEG is probably a useful backup monitor, but may miss subcortical events. Transcranial Doppler ultrasound flow velocity is less useful since flow in the MCAis not a direct reflection of CBF at cortical level. Transcranial Doppler ultrasound detects intraoperative emboli but the value of this observation is unclear.

The low incidence of intraoperative stroke in the present series, and the absence of stroke in other reports of multimodality monitoring, requires that conclusions must be tentative until a larger experience of simultaneous application of standardized monitoring methods can be accumulated.

Somatosensory evoked potentials and EEG can be recorded consistently under general anaesthesia. In our hands, transcranial Doppler ultrasound is less reliably obtained.
Clinically significant ischemia during carotid endarterectomy is relatively infrequent.

Persistent amplitude decrease of $>50 \%$ in SSEPfor the entire period of carotid occlusion, correlates strongly with immediate cerebral infarction and appears to be the most reliable of the three monitoring modes evaluated for detection of significant intraoperative cerebral ischemia. Because of the small number of disagreements between modalities, a larger cohort of patients would be required to conclusively demonstrate the superiority of SSEP.

Persistent amplitude decrease of $>75 \%$ in continuous EEG and TCD flow velocity are less reliable predictors of immediate cerebral infarction. Because EEG can be consistently recorded intraoperatively, it is a useful backup to SSEP.

Transcranial Doppler may show a marked reduction in flow velocity in the MCA, while SSEP and EEG remain unchanged. This probably reflects well-preserved CBF at cortical level due to adequate collateral pathways since TCD change alone was not associated with new postoperative neurological deficits and, therefore, is an uncertain indicator of cerebral ischemia.

Transcranial Doppler detected emboli during one quarter of the CEAs performed but was not associated with new neurological deficits in any patient. Although most intraoperative cerebral infarctions are probably caused by emboli, the predictive value of TCD appears to be limited.

Positioning and patency of intraluminal shunts should be checked if SSEP changes persist after shunt placement.

\section{ACKNOWLEDGEMENTS}

We thank Dr. Venemreddy Prasad for his participation in the planning of the project, and Catherine Munro for her assistance in the preparation of this manuscript.

\section{REFERENCES}

1. Spielberger L, Turndorf H, Culliford A, Imparato A. Hand-held toy squeaker during carotid endarterectomy in the awake patient. Arch Surg 1979; 114: 103-104.

2. Spencer MP, Thomas GI, Moehring MA. Relation between middle cerebral artery blood flow velocity and stump pressure during carotid endarterectomy. Stroke 1992; 23: 1439-1445.

3. Whitley D, Cherry KJ Jr. Predictive value of carotid artery stump pressures during carotid endarterectomy. Neurosurg Clin N Am 1996; 7: 723-732.

4. Blume WT, Ferguson GG, McNeill DK. Significance of EEG changes at carotid endarterectomy. Stroke 1986; 17: 891-897.

5. Blume WT, Sharbrough FW. EEG Monitoring during Carotid Endarterectomy and Open Heart Surgery. In: Niedermeyer E, Lopes Da Silva F, (Eds). Electroencephalography: Basic Principles, Clinical Applications, and Related Fields. Baltimore: Williams and Wilkins, 1999: 797-808.

6. Chiappa KH, Burke SR, Young RR. Results of electroencephalographic monitoring during 367 carotid endarterectomies. Use of a dedicated minicomputer. Stroke 1979; 10: 381-388.

7. Jansen C, Vriens EM, Eikelboom BC, et al. Carotid endarterectomy with transcranial Doppler and electroencephalographic monitoring. A prospective study in 130 operations. Stroke 1993; 24: 665-669.

8. Sturzenegger AM, Schaffler L, Seiler RW. Continuous intraoperative monitoring of middle cerebral artery blood flow velocity and electroencephalography during carotid endarterectomy. A comparison of methods to detect cerebral ischemia. Stroke 1997; 28: 1345-1350.

9. Tempelhoff R, Modica PA, Grubb RL Jr, et al. Selective shunting 
during carotid endarterectomy based on two-channel computerized electroencephalographic/compressed spectral array analysis. Neurosurgery $1989 ; 24: 339-344$.

10. Halsey JH, McDowell HA, Gelman S. Transcranial Doppler and rCBF compared in carotid endarterectomy. Stroke 1986; 17: 1206-1208.

11. Rowed DW, Vilaghy MI. Intraoperative regional cerebral blood flow during carotid endarterectomy. Can J Neurol Sci 1981; 8: 235-241.

12. Guerit JM, Witdoeckt C, de Tourtchaninoff M, et al. Somatosensory evoked potential monitoring in carotid surgery. I. Relationships between qualitative SEP alterations and intraoperative events. Electroencephalogr Clin Neurophysiol 1997; 104: 459-469.

13. Haupt WF, Horsch S. Evoked potential monitoring in carotid surgery: a review of 994 cases. Neurology 1992; 42: 835-838.

14. Horsch S, Ktenidis K. Intraoperative use of somatosensory evoked potentials for brain monitoring during carotid surgery. Neurosurg Clin N Am 1996; 7: 693-702.

15. Lam AM, Manninen PH, Ferguson GG, Nantau W. Monitoring electrophysiologic function during carotid endarterectomy: a comparison of somatosensory evoked potentials and conventional electroencephalogram. Anesthesiology 1991; 75: $15-21$.

16. Manninen PH, Tan TK, Sarjeant RM. Somatosensory evoked potential monitoring during carotid endarterectomy in patients with a stroke. Anesth Analg 2001; 93: 39-44.

17. Aackerstaff RG, Jansen C, Moll FL. Carotid Endarterectomy and Intraoperative Emboli Detection: Correlation of Clinical, Transcranial Doppler, and Magnetic Resonance Findings. Echocardiography 1996; 13: 543-550.

18. Bass A, Krupski WC, Schneider PA, et al. Intraoperative transcranial Doppler: limitations of the method. J Vasc Surg 1989; 10: 549-553.

19. Gaunt ME. Transcranial Doppler: preventing stroke during carotid endarterectomy. Ann R Coll Surg Engl 1998; 80: 377-387.

20. Jorgensen LG. Transcranial Doppler ultrasound for cerebral perfusion. Acta Physiol Scand Suppl 1995; 625: 1-44.

21. Lacroix $H$, Beyens $G$, Van Hemelrijck $J$, et al. Is transcranial Doppler useful in the detection of internal carotid artery crossclamp intolerance? Cardiovasc Surg 1999; 7: 203-207.

22. Naylor AR, Hayes PD, Allroggen H, et al. Reducing the risk of carotid surgery: a 7-year audit of the role of monitoring and quality control assessment. J Vasc Surg 2000; 32: 750-759.

23. Smith JL, Evans DH, Gaunt ME, et al. Experience with transcranial Doppler monitoring reduces the incidence of particulate embolization during carotid endarterectomy. Br J Surg 1998; 85: 56-59.

24. Carlin RE, McGraw DJ, Calimlim JR, Mascia MF. The use of nearinfrared cerebral oximetry in awake carotid endarterectomy. J Clin Anesth 1998; 10: 109-113.

25. Samra SK, Dy EA, Welch K, et al. Evaluation of a cerebral oximeter as a monitor of cerebral ischemia during carotid endarterectomy. Anesthesiology 2000; 93: 964-970.

26. Niinai H, Nakagawa I, Shima T, et al. Continuous monitoring of jugular bulb venous oxygen saturation for evaluation of cerebral perfusion during carotid endarterectomy. Hiroshima J Med Sci 1998; 47: 133-137.

27. Thiel A, Ritzka M. Cerebral monitoring in carotid surgery. Results of a questionnaire in the Federal Republic of Germany. Anasthesiol Intensivmed Notfallmed Schmerzther 2001; 36: 693697.

28. Rowed DW, Houlden DA, Burkholder LM. Comparative value of somatosensory evoked potentials (SSEP), electroencephalography (EEG), and transcranial Doppler (TCD) for detection of intraoperative cerebral ischemia. Can J Neurol Sci 2001; 28: S10.

29. Duffy CM, Manninen PH, Chan A, Kearns CF. Comparison of cerebral oximeter and evoked potential monitoring in carotid endarterectomy. Can J Anaesth 1997; 44: 1077-1081.
30. North American Symptomatic Carotid Endarterectomy Trial Collaborators. Beneficial effect of carotid endarterectomy in symptomatic patients with high-grade carotid stenosis. N Engl J Med 1991; 325: 445-453.

31. Jasper H. The ten-twenty electrode system of the International Federation. Electroencephalogr Clin Neurophysiol 1958; 10: 371-375.

32. Fiori L, Parenti G, Marconi F. Combined transcranial Doppler and electrophysiologic monitoring for carotid endarterectomy. J Neurosurg Anesthesiol 1997; 9: 11-16.

33. de Boorst GJ, Moll FL, van de Pavoordt HDWM. Stroke from carotid endarterectomy: when and how to reduce perioperative rate? Eur J Vasc Endovasc Surg 2001; 21: 484-489.

34. Haupt WF, Erasmi-Korber H, Lanfermann H. Intraoperative recording of parietal SEP can miss hemodynamic infarction during carotid endarterectomy: a case study. Electroencephalogr Clin Neurophysiol 1994; 92: 86-88.

35. Linstedt U, Maier C, Petry A. Intraoperative monitoring with somatosensory evoked potentials in carotid artery surgery--less reliable in patients with preoperative neurologic deficiency? Acta Anaesthesiol Scand 1998; 42: 13-16.

36. Sundt TM Jr, Sharbrough FW, Anderson RE, Michenfelder JD. Cerebral blood flow measurements and electroencephalograms during carotid endarterectomy. J Neurosurg 1974; 41: 310-320.

37. Fava E, Bortolani E, Ducati A, Schieppati M. Role of SEP in identifying patients requiring temporary shunt during carotid endarterectomy. Electroencephalogr Clin Neurophysiol 1992; 84: 426-432.

38. Schneider PA, Ringelstein EB, Rossman ME, et al. Importance of cerebral collateral pathways during carotid endarterectomy. Stroke 1988; 19: 1328-1334.

39. Lennard N, Smith J, Dumville J, et al. Prevention of postoperative thrombotic stroke after carotid endarterectomy: the role of transcranial Doppler ultrasound. J Vasc Surg 1997; 26: 579-584.

40 Thiel A, Russ W, Zeiler D, et al. Transcranial Doppler sonography and somatosensory evoked potential monitoring in carotid surgery. Eur J Vasc Surg 1990; 4: 597-602.

41. Dinkel M, Langer H, Loerler $\mathrm{H}$, et al. Neuromonitoring in carotid surgery: possibilities and limits of transcranial Doppler ultrasound. Vasa 1994; 23: 337-344.

42. Aackerstaff RG, Moons KG, van de Vlasakker CJ, et al. Association of intraoperative transcranial doppler monitoring variables with stroke from carotid endarterectomy. Stroke 2000; 31: 1817-1823.

43. Heyer EJ, Winfree CJ, Mack WJ, Connolly ES Jr. Transcranial Doppler monitoring during carotid endarterectomy: a technical case report. J Neurosurg Anesthesiol 2000; 12: 233-239.

44. Halsey JH, McDowell HA, Gelmon S, Morawetz RB. Blood velocity in the middle cerebral artery and regional cerebral blood flow during carotid endarterectomy. Stroke 1989; 20: 53-58.

45. Jansen C, Moll FL, Vermeulen FE, et al. Continuous transcranial Doppler ultrasonography and electroencephalography during carotid endarterectomy: a multimodal monitoring system to detect intraoperative ischemia. Ann Vasc Surg 1993; 7: 95-101.

46. Tegos TJ, Sabetai MM, Nicolaides AN, et al. Correlates of embolic events detected by means of transcranial Doppler in patients with carotid atheroma. J Vasc Surg 2001; 33: 131-138.

47. Dunne VG, Besser M, Ma WJ. Transcranial Doppler in carotid endarterectomy. J Clin Neurosci 2001; 8: 140-145.

48. Arnold M, Sturzenegger M, Schaffler L, Seiler RW. Continuous intraoperative monitoring of middle cerebral artery blood flow velocities and electroencephalography during carotid endarterectomy. A comparison of the two methods to detect cerebral ischemia. Stroke 1997; 28: 1345-1350.

49. Steiger HJ, Schaffler L, Boll J, Liechti S. Results of microsurgical carotid endarterectomy. A prospective study with transcranial Doppler and EEG monitoring, and elective shunting. Acta Neurochir (Wien ) 1989; 100: 31-38. 